\title{
Cancer risks among patients with type 2 diabetes: a 10-year follow-up study of a nationwide population-based cohort in Taiwan
}

\author{
Cheng-Chieh Lin ${ }^{1,2,3 \dagger}$, Jen-Huai Chiang ${ }^{4,5+}$, Chia-Ing Li ${ }^{2,3}$, Chiu-Shong Liu ${ }^{1,2,3}$, Wen-Yuan Lin ${ }^{1,2}$, \\ Teng-Fu Hsieh ${ }^{6,7,8}$ and Tsai-Chung $\mathrm{Li}^{4,9 *}$
}

\begin{abstract}
Background: This study aims to determine cancer risks among patients with type 2 diabetes through a follow-up study on a nationwide population-based cohort that included Taiwanese diabetic patients and general population in Taiwan as well as to estimate the population attributable fraction (PAF) of site-specific cancer risks that can be attributed to type 2 diabetes in Taiwanese population by using standardized incidence ratios (SIRs, 95\% Cl).

Methods: Subjects with type 2 diabetes consisted of 472,979 patients aged $\geq 20$ years, whereas general population consisted of 9,411,249 individuals of the same age limit but are not diabetic. Subjects were identified from 1997 to 1998 and followed up until December 31, 2007 or until the first manifestation of any cancer.

Results: Cancer sites with increased risks in men, which were consistent with the main and sensitivity analyses, included pancreas $(\mathrm{SIR}=1.62 ; 95 \% \mathrm{Cl}=1.53$ to 1.72$)$, liver $(1.61 ; 1.57$ to 1.64$)$, kidney $(1.32 ; 1.25$ to 1.40$)$, oral (1.16, 1.12 to 1.21$)$, and colorectal $(1.19,1.15$ to 1.22$)$. Cancer sites with increased risks in women included liver $(1.55 ; 1.51$ to 1.60$)$, pancreas $(1.44 ; 1.34$ to 1.55$)$, kidney $(1.38 ; 1.30$ to 1.46$)$, endometrium $(1.36 ; 1.26$ to 1.47$)$, bladder $(1.19 ; 1.11$ to 1.27$)$, colorectal $(1.16 ; 1.13$ to 1.20$)$, and breast $(1.14 ; 1.09$ to 1.18$)$. Overall, PAFs were highest for liver cancer in men (4.0\%) and women (3.7\%), followed by pancreas (3.4\%) and kidney (1.6\%) cancers in men, and then for endometrium (1.8\%) and kidney (1.8\%) cancers in women.
\end{abstract}

Conclusion: Our data suggested that increased cancer risks are associated with type 2 diabetes.

Keywords: T2DM, Cancer risks, Liver cancer, Colorectal cancer, Pancreas cancer, Breast cancer

\section{Background}

Diabetes is one of major public health problems in the world. The prevalence of type 2 diabetes mellitus has rapidly increased in Asian populations because of Westernized lifestyle behaviors [1]. Diabetes mellitus (DM) is also one of health burdens in Taiwan, and it ranks fifth among the top 10 leading causes of deaths in 2009. According to Taiwan National Health Insurance Research Database (NHIRD), age-standardized prevalence rates of type 2 diabetes have increased from $5.7 \%$ to $8.6 \%$ for

\footnotetext{
* Correspondence: tcli@mail.cmu.edu.tw

${ }^{\dagger}$ Equal contributors

${ }^{4}$ Graduate Institute of Biostatistics, College of Management, China Medical University, 91 Hsueh-Shih Road, Taichung 40421, Taiwan

${ }^{9}$ Department of Healthcare Administration, College of Health Science, Asia University, Taichung, Taiwan

Full list of author information is available at the end of the article
}

men and from $5.9 \%$ to $8.0 \%$ for women from 2000 to 2007 [2]. In addition, new type 2 diabetes cases in younger adult population have increased [3]. Prevalence of diabetes is also indicated in the Taiwanese Survey on Hypertension, Hyperglycemia, and Hyperlipidemia, where diabetes incidence is $7.5 \%$ in male and $6.8 \%$ in female from 2002 to 2007 [4].

Epidemiological findings of cohort and case-control studies have reported possible association between type 2 diabetes and several cancer types, which include colon $[5,6]$, liver $[7,8]$, pancreatic $[9,10]$, breast $[11]$ and prostate cancers $[12,13]$. DM and cancers have common risk factors, such as smoking, alcohol consumption, obesity, diet, physical inactivity, high calorie intake, and saturated fat intake [14]. Moreover, several possible biological mechanisms that are likely involved in the 
association between diabetes and cancer have been proposed [15-17].

Previous studies have reported on estimated standardized incidence ratios (SIRs) by adjusting population structure for site-specific cancers in patients with DM, including those in Sweden [6,18], China [18], USA [5], and Denmark [19]. SIRs are useful for researchers, policy-makers, and health-care planners to describe the health status of a given population for planning necessary medical care services. However, studies on estimating SIRs for all site-specific cancers in Taiwanese have never been conducted. Several studies on the association of type 2 diabetes with cancers in Taiwan have focused on one specific cancer site, such as the prostate [20], colon [21], liver [22], and breast [23]. However, none of these studies have considered all cancer types simultaneously. Thus, the present study specifically aims to estimate cancer risks among patients with type 2 diabetes through a follow-up study on a national populationbased cohort that include all Taiwanese diabetic patients and general population in Taiwan as well as to estimate population attributable fractions (PAF) of site-specific cancer risks in Taiwan population that can be attributed to type 2 diabetes by using SIRs .

\section{Methods}

\section{Data sources}

A national health insurance program was implemented in March 1995 [24]. In 2007, 22.6 million individuals from a total population of 23.0 million in Taiwan were enrolled in this insurance program. The Bureau of National Health Insurance (BNHI) contracted with 97\% of hospitals and $92 \%$ of clinics in Taiwan. The datasets of the study consisted of registry for beneficiaries, ambulatory and inpatient care claims, and Registry for Catastrophic Illness from 1996 to 2007 from NHIRD. BNHI performs quarterly expert reviews on random samples of every 50 to 100 ambulatory and inpatient claims in each hospital and clinic. False diagnosis reports entail a high penalty.

Every individual in Taiwan has a unique personal identification number (PIN) code. To protect privacy, data on patient identities are scrambled cryptographically by NHIRD. All the datasets can be interlinked through each individual PIN. Ambulatory care claims contain individual's gender and birthday, date of visit, and codes for the International Classification of Diseases, Ninth Revision, Clinical Modification (ICD-9-CM) codes, or A-codes for three primary diagnoses. Inpatient claims contain ICD-9CM codes for principal diagnosis up to four secondary diagnoses. Registry for Catastrophic Illness database contains data from insurers who suffer from major diseases and are granted exemption from co-payment. All cancer cases registered in the catastrophic illness database should be confirmed by pathological reports. Our study using these data was exempted from institutional review board approval of Public Health, Social and Behavioral Science Committee Research Ethics Committee, China Medical University and Hospital.

We conducted a population-based cohort study of two groups. Patients with type 2 diabetes (aged $\geq 20$ years) were identified in 1997 to 1998 and followed up until December 31, 2007 or until the first manifestation of any cancer type. Population with type 2 diabetes should have at least three ambulatory claims or at least one inpatient claim with diagnosis of ICD-9-CM code 250 or A-code A181 from 1997 to 1998. To exclude those individuals with type 1 diabetes, we have done two steps. First, we identify all individuals with type 1 diabetes from Registry for Catastrophic Illness database. Second, we excluded those individuals with type 1 diabetes identified in the first step from our study cohort with diabetes. We initially excluded subjects with type 1 diabetes $(\mathrm{N}=3,750)$, any cancer type $(\mathrm{N}=135,060)$, and those aged $<20$ years $(\mathrm{N}=17,679)$ at baseline from 633,680 patients with type 2 diabetes aged $\geq 20$ years. We further excluded those with incomplete information for gender and area registered for NIH program $(\mathrm{N}=$ 4,212 ). The other group was general population, which comprised all insured individuals of the same age without any diabetes. The baseline date or index date for type 2 diabetes group was date of the first outpatient visit or inpatient admission. For general population, the index date was randomly assigned between January 1, 1997 and December 31, 1998 according to index date distribution of type 2 diabetes group. A total of $21,680,686$ subjects were obtained from insured population in the data (Figure 1), and we excluded subjects with type 1 diabetes $(\mathrm{N}=8,910)$, any cancer at baseline $(\mathrm{N}=2,401,786)$, any diabetes $(\mathrm{N}=2,735,586)$ from 1996 to 2007, and individuals aged $<20$ years $(\mathrm{N}=7,055,840)$. Those with incomplete information for gender and area registered for $\mathrm{NIH}$ program $(\mathrm{N}=67,315)$ from 1997 to 1998 were also excluded. Thus, 472,979 patients with type 2 diabetes and 9,411,249 individuals without any diabetes from 1997 to 1998 were included in final analysis.

\section{Measurements}

Sociodemographic factors include age, gender, insurance premium, and urbanization degree of area registered for $\mathrm{NIH}$ program. Age was divided into 17 groups with fiveyear intervals from 20 to $>90$ years. Gender was categorized into male and female. Insurance premium was categorized according to median of the amounts of insurance premiums, in which median value for these two groups was both 19,200 NT dollars from 1997 to 1998 . We used an urbanization indicator developed by Liu et al. [25], who categorized 365 Taiwan towns into seven 


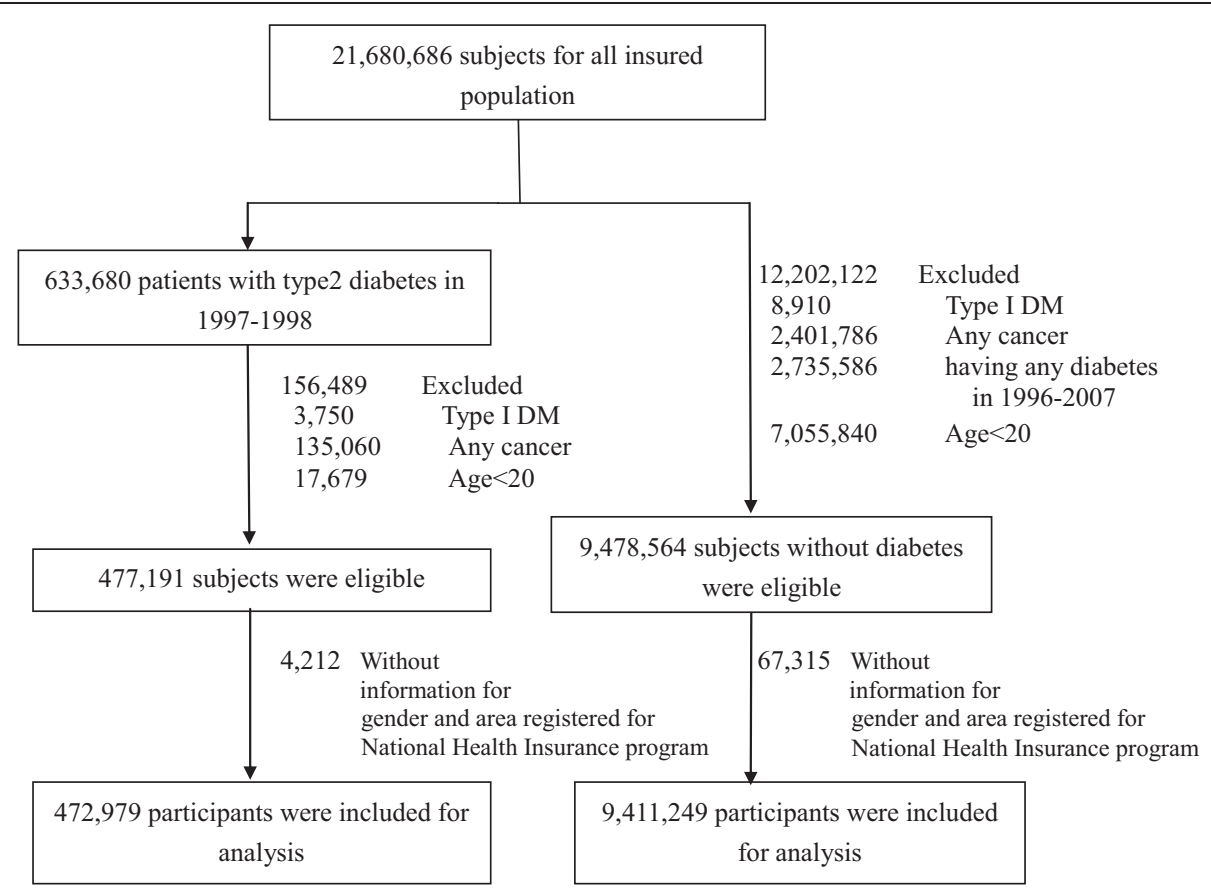

Figure 1 Flowchart of recruitment procedures for the current study.

degrees of urbanization: high- and medium-density urban areas, newly developed area, general area, aging-society area, rural area, and non-developed area.

Cancer cases were identified from ambulatory and inpatient care claims of NHIRD from 1999 to 2007. Incidence rates of lung cancer (ICD-9 code 162; A-code A101), liver cancer (ICD-9 codes 155; A-code A095), colorectal cancer (ICD-9 codes 153, 154; A-code A093, A094), breast cancer (ICD-9 code 174; A-code A113), gastric cancer (ICD-9 code 151; A-code A091), oral cancer (ICD-9 codes 140 to 141, 143 to 146,148 to 149 ; A-code A08), prostate cancer (ICD9 code 185; A-code A124), esophageal cancer (ICD-9 code 150; A-code A090), pancreatic cancer (ICD-9 code 157; Acode A096), cervical cancer (ICD-9 codes 179, 180; A-code A120), nasopharyngeal cancer (ICD-9 code 147; A-code A08-01), small intestine, including duodenum cancer (ICD9 code 152; A-code A092), gallbladder cancer (ICD-9 code 156; A-code A099-02), retroperitoneum and peritoneum cancers (ICD-9 code 158; A-code A099), laryngeal cancer (ICD-9 code 161; A-code A100), respiratory and intrathoratic organ cancers (ICD-9 codes 160, 163 to 165; A-code A109), bone cancer (ICD-9 code 170; A-code A110), connective and other soft tissue cancers (ICD-9 code 171; Acode A114), skin cancer (ICD-9 code 172; A-code A111), placenta cancer (ICD-9 code 181; A-code A121), endometrial cancer (ICD-9 code 182; A-code A122-01), ovarian cancer (ICD-9 code 183; A-code A123), testicular cancer (ICD-9 code 186; A-code A125), penile cancer (ICD-9 code 187; A-code A129-02), bladder cancer (ICD-9 code 188; A-code A126), kidney cancer (ICD-9 code 189; A-code
A129-04), brain cancer (ICD-9 code 191; A-code A130), Hodgkin's disease (ICD-9 code 201; A-code A140), leukemia (ICD-9 codes 204 to 208; A-code A141), and carcinoma in situ (ICD-9 codes 230 to 234; A-code A16) were estimated for type 2 diabetes group and general population. The incidence rates of cancers were estimated using number of new cancer cases identified by NHIRD from 1999 to 2007 as numerators and total person-years from individuals with type 2 diabetes and without any diabetes during follow-up period as denominators.

\section{Statistical analysis}

Person-years of two populations were calculated from baseline to the occurrence of specific cancers or closing date (December 31, 2007). SIRs and 95\% confidence intervals (CI) were estimated for cancers by using Poisson regression analysis and gender, area registered for NIH program, and age were adjusted. A sensitivity analysis was performed under two conditions. For the first condition, same comparisons were made except in the excluded cancer cases identified in 1999. These cancer cases were excluded because patients are very likely to have cancers at baseline and have not been diagnosed, thereby ruling out the possibility of effect-cause relationship between diabetes and cancer. The second condition included the use of Registry for Catastrophic Illness database to identify cancer cases confirmed by pathological reports to estimate SIRs. PAFs for sitespecific cancer incidence caused by diabetes were calculated for each gender by using previously published 
prevalence estimates of diabetes in Taiwan [2] using the same dataset as the current study with the following formula [26]:

PAF $=$ diabetes prevalence $\times(\mathrm{RR}-1) /[1+$ diabetes prevalence $\times(R R-1)]$. All statistical analyses were performed using SAS version 9.2 software (SAS Institute, Inc., Cary, $\mathrm{NC})$.

\section{Results}

Table 1 shows baseline characteristics of individuals according to type 2 diabetes status stratified by gender in Taiwan. Sex-specific incidence density rates and SIRs for cancer sites from main and sensitivity analyses are shown in Table 2. Cancer sites with increased risks, which were consistent with main and sensitivity analyses, included liver $(\mathrm{SIR}=1.61 ; 95 \% \mathrm{CI}=1.57$ to 1.64 for the main analysis), colorectal $(\mathrm{SIR}=1.19 ; 95 \% \mathrm{CI}=$ 1.15 to 1.22 ), oral $(\mathrm{SIR}=1.16 ; 95 \% \mathrm{CI}=1.12$ to 1.21 ), pancreas ( $\mathrm{SIR}=1.62 ; 95 \% \mathrm{CI}=1.53$ to 1.72 ), and kidney $(\mathrm{SIR}=1.32 ; 95 \% \mathrm{CI}=1.25$ to 1.40$)$ for men. A significant decrease was observed in prostate $(\mathrm{SIR}=0.96$; $95 \% \mathrm{CI}=0.93$ to 0.99$)$, esophageal $(\mathrm{SIR}=0.88 ; 95 \% \mathrm{CI}=$ 0.82 to 0.94 ), and laryngeal ( $\mathrm{SIR}=0.84 ; 95 \% \mathrm{CI}=0.77$ to $0.91)$ cancer incidences for men. For women, cancer sites with increased risks include liver ( $\mathrm{SIR}=1.55 ; 95 \% \mathrm{CI}=1.51$ to 1.60 for main analysis), colorectal ( $\mathrm{SIR}=1.16$; $95 \% \mathrm{CI}=$ 1.13 to 1.20 ), breast ( $\mathrm{SIR}=1.14 ; 95 \% \mathrm{CI}=1.09$ to 1.18 ), pancreas $(\mathrm{SIR}=1.44 ; 95 \% \mathrm{CI}=1.34$ to 1.55$)$, endometrium $(\mathrm{SIR}=1.36 ; 95 \% \mathrm{CI}=1.26$ to 1.47$)$, bladder $(\mathrm{SIR}=1.19 ; 95 \%$ $\mathrm{CI}=1.11$ to 1.27$)$, and kidney $(\mathrm{SIR}=1.38 ; 95 \% \mathrm{CI}=1.30$ to 1.46). A significant decrease was observed in cervix $(\mathrm{SIR}=0.94 ; 95 \% \mathrm{CI}=0.91$ to 0.99$)$ and connective and other soft tissue $(\mathrm{SIR}=0.86 ; 95 \% \mathrm{CI}=0.76$ to 0.97 ) cancer incidences. Using Registry for Catastrophic Illness database to identify the cancer cases, SIRs that were not significant, but were significant in main analysis and sensitivity analysis that excluding cancer cases diagnosed within one year of entry included: 1) gallbladder and penile cancers, as well as Hodgkin's disease, leukemia, and carcinoma in situ in men; and 2) stomach, oral, larynx, and placenta cancers, Hodgkin's disease, leukemia, and carcinoma in situ in women.

Figure 2 shows PAF of site-specific cancer risks that were consistent with main and sensitivity analyses and seemed to have notable associations with diabetes, such as liver, colorectal, oral, pancreas, and kidney for men, and liver, colorectal, breast, pancreas, endometrium, bladder, and kidney for women. These PAFs differed substantially across cancer sites (Figure 2). Overall, PAFs were highest for liver cancer in men $(4.0 \%)$ and women (3.7\%), followed by pancreas (3.4\%) and kidney (1.6\%) cancers in men, and endometrium (1.8\%) and kidney (1.8\%) cancers in women.

\section{Discussion}

To the best of our knowledge, this report is the largest study to examine SIRs and PAFs of diabetes on sitespecific cancer incidence for Taiwanese population. This nationwide population-based cohort study included 474,686 patients with type 2 diabetes whose ages were $\geq 20$ years at baseline. General population consists of approximately 10 million individuals who enrolled in NHI program with the same age limits but with no diabetes. All individuals in this study have been followed up for 10 to 11 years. In this retrospective nationwide population study, a diagnosis of DM was associated with $61 \%, 19 \%, 16 \%, 62 \%$, and $32 \%$ increases in risks of liver, colorectal, oral, pancreatic, and kidney cancer incidences in Taiwanese men, respectively. A similar result was also observed in women, in which $55 \%$, $16 \%, 14 \%, 44 \%, 36 \%, 19 \%$, and $38 \%$ increases in liver, colorectal, breast, pancreas, endometrium, bladder, and kidney cancers were observed, respectively. This study showed similarity in magnitude of risks between men and women. Our study provided estimates for site-specific cancer risks for Taiwanese with type 2 diabetes by adjusting for population structure. In particular, association between diabetes and oral cancer has never been reported. Furthermore, proportions of total risks for site-specific cancers in Taiwanese population that can be attributed to type 2 diabetes were estimated using the entire populations with and without type 2 diabetes.

Studies on the relationship between diabetes and cancer using SIRs have indicated that diabetes has an increased risk of liver [6], colon [5,6,18], pancreas [6], esophagus [6], stomach [6], and lung [6], cancers, whereas risk of prostate cancer is lower [6]. Diabetes is also associated with higher risk of breast cancer according to several studies [6]. By contrast, other studies have shown that diabetes is associated with lower risk for breast cancer [27]. The findings regarding increased risks of liver, colorectal, pancreatic, and kidney cancers are consistent with those in previous studies [28-34]. We also observed higher risks of breast, bladder, and endometrium cancers in women, which is consistent with findings from previous studies [19]. A significant inverse association between diabetes and prostate cancer has been observed in men, which is also consistent with previous epidemiological studies [19,35-38], but inconsistent with those that show no associations [30-34,39]. At the other sites, we found a negative association for esophageal and laryngeal cancers in males, as well as for cervical and connective and other soft tissue cancers in females. However, previous epidemiological studies [30-34,40,41] have found no evidence for an association with these cancers, although several studies have shown negative associations [19]. 


\begin{tabular}{|c|c|c|c|c|}
\hline & \multicolumn{4}{|c|}{ Gender } \\
\hline & \multicolumn{2}{|c|}{ Men } & \multicolumn{2}{|c|}{ Women } \\
\hline & General population (\%) & Type2 diabetes (\%) & General population (\%) & Type2 diabetes (\%) \\
\hline & $N=5,185,732$ & $N=233,506$ & $N=4,225,517$ & $N=239,473$ \\
\hline \multicolumn{5}{|l|}{ Age } \\
\hline $20-24$ & $635,139(12.25)$ & $543(0.23)$ & $541,889(12.82)$ & $532(0.22)$ \\
\hline $25-29$ & $853,765(16.46)$ & $1,543(0.66)$ & $679,275(16.08)$ & $1,605(0.67)$ \\
\hline $30-34$ & $836,516(16.13)$ & $4,150(1.78)$ & $676,492(16.01)$ & $3,039(1.27)$ \\
\hline $35-39$ & $752,396(14.51)$ & $9,642(4.13)$ & $622,116(14.72)$ & $5,366(2.24)$ \\
\hline $40-44$ & $615,146(11.86)$ & $17,613(7.54)$ & $500,234(11.84)$ & $10,357(4.32)$ \\
\hline $45-49$ & $431,072(8.31)$ & $25,831(11.06)$ & $342,065(8.10)$ & $18,001(7.52)$ \\
\hline $50-54$ & $240,445(4.64)$ & $24,387(10.44)$ & $195,267(4.62)$ & $23,547(9.83)$ \\
\hline $55-59$ & $221,643(4.27)$ & $29,662(12.70)$ & $192,694(4.56)$ & $34,299(14.32)$ \\
\hline $60-64$ & $176,070(3.4)$ & $31,195(13.36)$ & $148,673(3.52)$ & $39,859(16.64)$ \\
\hline $65-69$ & $171,633(3.31)$ & $36,445(15.61)$ & $114,456(2.71)$ & $40,252(16.81)$ \\
\hline $70-74$ & $124,652(2.40)$ & $28,984(12.41)$ & $84,367(2.00)$ & $31,256(13.05)$ \\
\hline 75-79 & $72,715(1.40)$ & $15,164(6.49)$ & $60,737(1.44)$ & $18,873(7.88)$ \\
\hline $80-84$ & $37,193(0.72)$ & $6,148(2.63)$ & $39,697(0.94)$ & $8,721(3.64)$ \\
\hline 85-89 & $13,621(0.26)$ & $1,829(0.78)$ & $20,066(0.47)$ & $3,087(1.29)$ \\
\hline$\geq 90$ & $3,726(0.07)$ & $370(0.16)$ & $7,489(0.18)$ & $679(0.28)$ \\
\hline \multicolumn{5}{|l|}{ Insurance premiums } \\
\hline$<19200$ & $1,615,639(31.16)$ & $75,398(32.29)$ & $1,339,863(31.71)$ & $61,621(25.73)$ \\
\hline$\geq 19200$ & $3,570,093(68.84)$ & $158,108(67.71)$ & $2,885,654(68.29)$ & $177,852(74.27)$ \\
\hline \multicolumn{5}{|c|}{ Urbanization degree of area registered for National Health Insurance program } \\
\hline High density urban area & $1,551,499(30.28)$ & $63,914(27.64)$ & $1,398,129(33.52)$ & $61,109(25.82)$ \\
\hline Medium density urban area & $1,433,981(27.99)$ & $67,054(29.00)$ & $1,183,288(28.37)$ & $64,685(27.33)$ \\
\hline Newly developed area & $985,111(19.23)$ & $39,778(17.20)$ & $719,525(17.25)$ & $38,390(16.22)$ \\
\hline General area & $697,202(13.61)$ & $35,137(15.20)$ & $534,267(12.81)$ & $40,501(17.11)$ \\
\hline Aging society area & $90,159(1.76)$ & $6,204(2.68)$ & $69,560(1.67)$ & 7,877 (3.33) \\
\hline Rural area & $187,136(3.65)$ & $10,345(4.47)$ & 138,781 (3.33) & $13,034(5.51)$ \\
\hline Non-developed area & $178,634(3.49)$ & $8,803(3.81)$ & $127,110(3.05)$ & $11,096(4.69)$ \\
\hline
\end{tabular}


Table 2 Gender-specific incidence density rates and SIRs for cancer sites

\begin{tabular}{|c|c|c|c|c|c|c|c|c|c|c|}
\hline \multirow[b]{2}{*}{ Type of cancer } & \multicolumn{2}{|c|}{ General population $^{(a)}$} & \multicolumn{2}{|c|}{$\begin{array}{c}\text { Population with type2 } \\
\text { diabetes }\end{array}$} & \multicolumn{2}{|c|}{$\begin{array}{c}\text { Main analysis using } \\
\text { outpatient and inpatient } \\
\text { databases }\end{array}$} & \multicolumn{2}{|c|}{$\begin{array}{l}\text { After excluding cancer cases } \\
\text { diagnosed within } 1 \text { year of } \\
\text { entry }^{(b)}\end{array}$} & \multicolumn{2}{|c|}{$\begin{array}{l}\text { Using Registry for } \\
\text { Catastrophic Illness } \\
\text { Database }\end{array}$} \\
\hline & 0 & Incidence density & 0 & Incidence density ${ }^{\#}$ & SIR & $95 \% \mathrm{Cl}$ & SIR & $95 \% \mathrm{Cl}$ & SIR & $95 \% \mathrm{Cl}$ \\
\hline \multicolumn{11}{|l|}{ Men } \\
\hline Lung & 53072 & 1.14 & 7493 & 3.64 & 0.99 & $(0.97-1.02)$ & 0.96 & $(0.94-0.99)^{* *}$ & 0.74 & $(0.72-0.77)^{* * *}$ \\
\hline Liver & 64321 & 1.39 & 9375 & 4.57 & 1.61 & $(1.57-1.64)^{* * *}$ & 1.59 & $(1.55-1.62)^{* * *}$ & 1.70 & $(1.65-1.76)^{* * *}$ \\
\hline Colorectal & 46715 & 1.01 & 6048 & 2.92 & 1.19 & $(1.15-1.22)^{* * *}$ & 1.16 & $(1.13-1.20)^{* * *}$ & 1.12 & $(1.07-1.17)^{* * *}$ \\
\hline Stomach & 18918 & 0.41 & 2528 & 1.21 & 0.96 & $(0.92-1.00)^{*}$ & 0.96 & $(0.92-1.00)$ & 0.89 & $(0.85-0.95)^{* * *}$ \\
\hline Oral & 30942 & 0.67 & 2411 & 1.15 & 1.16 & $(1.12-1.21)^{* * *}$ & 1.15 & $(1.10-1.21)^{* * *}$ & 1.09 & $(1.03-1.15)^{* *}$ \\
\hline Prostate & 27767 & 0.60 & 4259 & 2.05 & 0.96 & $(0.93-0.99)^{*}$ & 0.94 & $(0.91-0.97)^{* * *}$ & 0.89 & $(0.85-0.94)^{* * * *}$ \\
\hline Esophagus & 11667 & 0.25 & 1073 & 0.51 & 0.88 & $(0.82-0.94)^{* * *}$ & 0.88 & $(0.82-0.94)^{* * *}$ & 0.69 & $(0.63-0.75)^{* * *}$ \\
\hline Pancreas & 7023 & 0.15 & 1337 & 0.64 & 1.62 & $(1.53-1.72)^{* * *}$ & 1.56 & $(1.46-1.67)^{* * *}$ & 1.60 & $(1.45-1.77)^{* * *}$ \\
\hline Cervix & - & - & - & - & - & - & - & - & - & - \\
\hline Nasopharyngeal & 20022 & 0.43 & 1251 & 0.60 & 1.09 & $(1.03-1.16)^{* * *}$ & 1.04 & $(0.98-1.11)$ & 0.85 & $(0.76-0.95)^{* *}$ \\
\hline Small intestine & 2129 & 0.05 & 287 & 0.14 & 1.15 & $(1.02-1.31)^{*}$ & 1.11 & $(0.97-1.28)$ & 0.82 & $(0.64-1.05)$ \\
\hline Gallbladder & 4522 & 0.10 & 693 & 0.33 & 1.18 & $(1.08-1.28)^{* * *}$ & 1.15 & $(1.05-1.25)^{* *}$ & 1.10 & $(0.97-1.25)$ \\
\hline Retroperitoneum and peritoneum & 1274 & 0.03 & 160 & 0.08 & 1.19 & $(1.00-1.40)^{*}$ & 1.14 & $(0.95-1.37)$ & 1.06 & $(0.74-1.51)$ \\
\hline Larynx & 6821 & 0.15 & 596 & 0.28 & 0.84 & $(0.77-0.91)^{* * *}$ & 0.83 & $(0.79-0.91)^{* * *}$ & 0.75 & $(0.65-0.85)^{* * *}$ \\
\hline Respiratory and intrathoratic organs & 7399 & 0.16 & 745 & 0.36 & 0.93 & $(0.86-1.00)$ & 0.90 & $(0.83-0.98)^{*}$ & 0.81 & $(0.65-1.00)^{*}$ \\
\hline Bone & 3778 & 0.08 & 350 & 0.17 & 0.93 & $(0.83-1.04)$ & 0.90 & $(0.79-1.01)$ & 0.90 & $(0.64-1.26)$ \\
\hline Connective and other soft tissue & 4536 & 0.10 & 428 & 0.20 & 1.07 & $(0.96-1.18)$ & 1.06 & $(0.95-1.18)$ & 0.81 & $(0.64-1.03)$ \\
\hline Skin & 1605 & 0.03 & 199 & 0.09 & 1.10 & $(0.95-1.28)$ & 1.08 & $(0.92-1.27)$ & 1.10 & $(0.85-1.43)$ \\
\hline Testis & 2017 & 0.04 & 127 & 0.06 & 1.16 & $(0.96-1.40)$ & 1.18 & $(0.97-1.44)$ & 0.71 & $(0.34-1.47)$ \\
\hline Penis & 1132 & 0.02 & 148 & 0.07 & 1.88 & $(1.57-2.25)^{* * *}$ & 1.41 & $(1.16-1.71)^{* * *}$ & 1.32 & $(0.96-1.82)$ \\
\hline Bladder & 12758 & 0.27 & 1802 & 0.86 & 1.07 & $(1.02-1.13)^{* *}$ & 1.04 & $(0.99-1.10)$ & 0.99 & $(0.92-1.06)$ \\
\hline Kidney & 9913 & 0.21 & 1504 & 0.72 & 1.32 & $(1.25-1.40)^{* * *}$ & 1.30 & $(1.22-1.38)^{* * *}$ & 1.28 & $(1.17-1.40)^{* * *}$ \\
\hline Brain & 7596 & 0.16 & 732 & 0.35 & 1.03 & $(0.96-1.12)$ & 0.99 & $(0.91-1.08)$ & 0.77 & $(0.65-0.92)^{* *}$ \\
\hline Hodgkin's disease & 760 & 0.02 & 106 & 0.05 & 1.69 & $(1.37-2.10)^{* * *}$ & 1.42 & $(1.11-1.81)^{* *}$ & 1.05 & $(0.63-1.73)$ \\
\hline Leukemia & 4917 & 0.11 & 928 & 0.44 & 1.86 & $(1.73-2.00)^{* * *}$ & 1.66 & $(1.54-1.80)^{* * *}$ & 0.96 & $(0.84-1.09)$ \\
\hline Carcinoma in situ & 11323 & 0.24 & 1251 & 0.60 & 1.18 & $(1.11-1.25)^{* * *}$ & 1.15 & $(1.07-1.23)^{* * *}$ & 0.81 & $(0.18-3.58)$ \\
\hline \multicolumn{11}{|l|}{ Women } \\
\hline Lung & 24872 & 0.66 & 4498 & 2.11 & 0.98 & $(0.95-1.02)$ & 0.97 & $(0.94-1.00)$ & 0.74 & $(0.70-0.78)^{* * *}$ \\
\hline Liver & 28577 & 0.75 & 6061 & 2.85 & 1.55 & $(1.51-1.60)^{* * *}$ & 1.54 & $(1.49-1.58)^{* * *}$ & 1.67 & $(1.60-1.75)^{* * *}$ \\
\hline
\end{tabular}


Table 2 Gender-specific incidence density rates and SIRs for cancer sites (Continued)

\begin{tabular}{|c|c|c|c|c|c|c|c|c|c|c|}
\hline Colorectal & 33469 & 0.88 & 5502 & 2.59 & 1.16 & $(1.13-1.20)^{* * *}$ & 1.15 & $(1.11-1.18)^{* * *}$ & 1.07 & $(1.01-1.12)^{* * *}$ \\
\hline Breast & 42441 & 1.12 & 2934 & 1.37 & 1.14 & $(1.09-1.18)^{* * *}$ & 1.13 & $(1.09-1.18)^{* * *}$ & 1.09 & $(1.04-1.14)^{* * *}$ \\
\hline Stomach & 9632 & 0.25 & 1830 & 0.85 & 1.11 & $(1.05-1.17)^{* * *}$ & 1.12 & $(1.06-1.18)^{* * *}$ & 1.05 & $(0.98-1.13)$ \\
\hline Oral & 4970 & 0.13 & 733 & 0.34 & 1.30 & $(1.20-1.42)^{* * *}$ & 1.27 & $(1.16-1.39)^{* * *}$ & 1.08 & $(0.94-1.25)$ \\
\hline Esophagus & 7500 & 0.20 & 648 & 0.30 & 1.08 & (0.99-1.18) & 1.06 & $(0.97-1.16)$ & 0.70 & $(0.54-0.90)^{* *}$ \\
\hline Pancreas & 4700 & 0.12 & 1071 & 0.50 & 1.44 & $(1.34-1.55)^{* * *}$ & 1.42 & $(1.32-1.53)^{* * *}$ & 1.31 & $(1.17-1.46)^{* * *}$ \\
\hline Cervix & 27472 & 0.73 & 2579 & 1.21 & 0.94 & $(0.90-0.99)^{* *}$ & 0.93 & $(0.89-0.98)^{* *}$ & 0.84 & $(0.79-0.90)^{* * *}$ \\
\hline Nasopharyngeal & 8789 & 0.23 & 690 & 0.32 & 1.14 & $(1.05-1.24)^{* *}$ & 1.09 & $(0.99-1.19)$ & 0.98 & $(0.82-1.18)$ \\
\hline Small intestine & 1248 & 0.03 & 222 & 0.10 & 1.11 & $(0.96-1.29)$ & 1.04 & $(0.88-1.22)$ & 1.04 & $(0.81-1.34)$ \\
\hline Gallbladder & 3278 & 0.09 & 697 & 0.32 & 1.10 & $(1.01-1.20)^{*}$ & 1.08 & $(0.99-1.19)$ & 1.08 & $(0.96-1.22)$ \\
\hline Retroperitoneum and peritoneum & 1358 & 0.04 & 201 & 0.09 & 1.16 & $(0.99-1.35)$ & 1.13 & $(0.95-1.33)$ & 1.16 & $(0.89-1.52)$ \\
\hline Larynx & 1272 & 0.03 & 137 & 0.06 & 1.30 & $(1.07-1.57)^{* *}$ & 1.35 & $(1.10-1.66)^{* *}$ & 1.41 & $(0.87-2.27)$ \\
\hline Respiratory and intrathoratic organs & 3889 & 0.10 & 495 & 0.23 & 0.94 & $(0.85-1.04)$ & 0.92 & $(0.83-1.02)$ & 0.66 & $(0.50-0.88)^{* *}$ \\
\hline Bone & 2555 & 0.07 & 333 & 0.15 & 1.03 & $(0.91-1.16)$ & 1.00 & $(0.88-1.14)$ & 0.78 & $(0.52-1.18)$ \\
\hline Connective and other soft tissue & 3284 & 0.09 & 309 & 0.14 & 0.86 & $(0.76-0.97)^{*}$ & 0.84 & $(0.73-0.95)^{* *}$ & 0.76 & $(0.58-0.99)^{*}$ \\
\hline Skin & 1265 & 0.03 & 189 & 0.09 & 1.10 & $(0.94-1.29)$ & 0.99 & $(0.83-1.18)$ & 0.93 & $(0.71-1.22)$ \\
\hline Placenta & 450 & 0.01 & 385 & 0.18 & 19.90 & $(16.40-24.16)^{* * *}$ & 8.74 & $(6.65-11.48)^{* * *}$ & 1.59 & $(0.44-5.74)$ \\
\hline Endometrium & 8094 & 0.21 & 835 & 0.39 & 1.36 & $(1.26-1.47)^{* * *}$ & 1.28 & $(1.18-1.39)^{* * *}$ & 1.32 & $(1.17-1.49)^{* * *}$ \\
\hline Ovary & 13406 & 0.35 & 873 & 0.41 & 1.02 & $(0.95-1.10)$ & 1.02 & $(0.94-1.10)$ & 0.85 & $(0.75-0.96)^{* *}$ \\
\hline Bladder & 6043 & 0.16 & 1151 & 0.54 & 1.19 & $(1.11-1.27)^{* * *}$ & 1.17 & $(1.09-1.25)^{* * *}$ & 1.13 & $(1.03-1.25)^{*}$ \\
\hline Kidney & 6943 & 0.18 & 1471 & 0.68 & 1.38 & $(1.30-1.46)^{* * *}$ & 1.36 & $(1.28-1.45)^{* * *}$ & 1.32 & $(1.21-1.45)^{* * *}$ \\
\hline Brain & 6370 & 0.17 & 791 & 0.37 & 1.15 & $(1.06-1.25)^{* * *}$ & 1.10 & $(1.01-1.20)^{*}$ & 0.80 & $(0.66-0.97)^{*}$ \\
\hline Hodgkin's disease & 543 & 0.01 & 91 & 0.04 & 1.84 & $(1.44-2.35)^{* * *}$ & 1.82 & $(1.38-2.39)^{* * * *}$ & 1.35 & $(0.64-2.87)$ \\
\hline Leukemia & 3353 & 0.09 & 830 & 0.39 & 2.11 & $(1.94-2.29)^{* * *}$ & 1.84 & $(1.68-2.03)^{* * *}$ & 0.96 & $(0.83-1.12)$ \\
\hline Carcinoma in situ & 49189 & 1.30 & 3142 & 1.47 & 0.93 & $(0.90-0.97)^{* * *}$ & 0.92 & $(0.88-0.96)^{* * *}$ & 1.05 & $(0.36-3.06)$ \\
\hline
\end{tabular}

(a) The SIR for general population is 1.00 .

(b) Observed number of cancer cases for population with type 2 diabetes after exclusion of cancers diagnosed within 1 year of cohort entry.

(') Observed number of cancer cases for population with type 2 diabetes using Registry of Catastrophic Illness Database

SIRs were adjusted for covariates (insurance premium, urbanization degree of area registered for National Health Insurance program, and age).

Bold type indicates that the $95 \%$ Cl does not include 1.00 . Abbreviations: $\mathrm{Cl}$ confidence interval, $\mathrm{O}$ observed number of cancer cases, SIR standardized incidence ratio. \#: per 1000 person-years; *: $\mathrm{p}<0.05$; **: $\mathrm{p}<0.01$;

Bold type indicate 


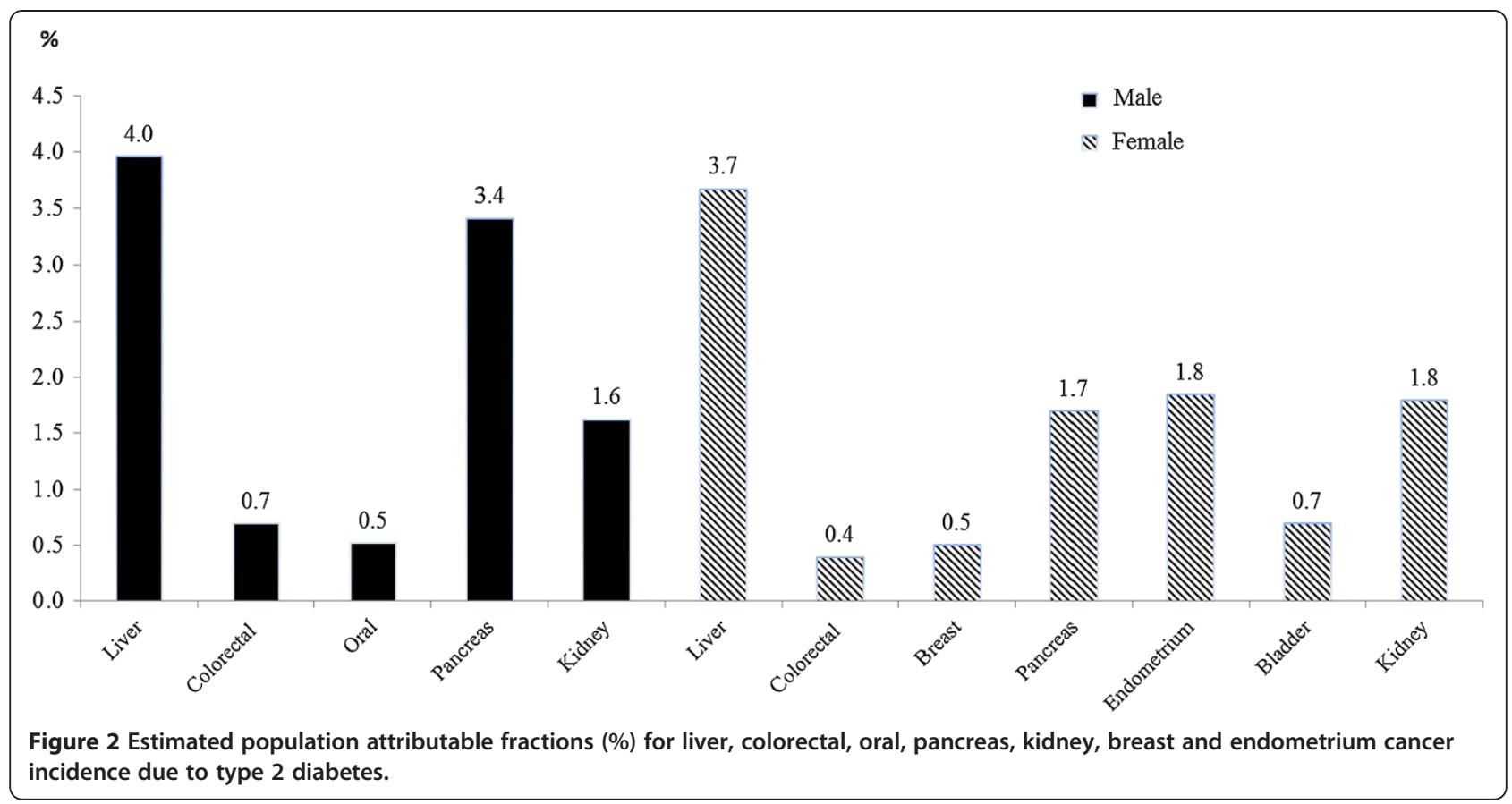

Our study, along with previous studies, indicated that diabetes is a risk factor for cancers. Many possible biological mechanisms are involved in the association between DM and overall or a specific cancer. Diabetes may influence cancer by hyperinsulinemia, hyperglycemia, or inflammation as a result of metabolic and hormonal aberrations [17]. Diabetic individuals normally have hyperinsulinemia and are associated with reduced insulin sensitivity and compensatory hyperinsulinemia as well as increased insulin-like growth factor (IGF)-1 levels, which may stimulate cell proliferation in liver, pancreas, colon, ovary, breast, and other areas. Insulin and IGFs may promote tumor cell growth, which increases risk of cancers. Among cancers that we have studied, liver and pancreatic cancers were the two types that exhibited the highest SIRs associated with type 2 diabetes. Insulin is produced by pancreatic $\beta$ cells through hepatic portal vein to liver, which, along with pancreas, is exposed to high insulin concentrations [17]. Considering inflammatory function of insulin, previous studies have shown a strong association between obesity and diabetes [15]. Obesity may increase risk of cancers because obese individuals have higher levels of leptin and lower levels of serum adiponectin [16], which is associated with chronic inflammation [42]. Association between DM and cancer can also be associated with the changes in sex hormone levels that occur in several types of cancer, such as prostate cancer. Testosterone affects the growth of prostate gland [43]; in particular, a high testosterone level is associated with prostate cancer [44]. Previous studies have also indicated that diabetic men have lower testosterone levels [45], which suggest a decreased risk in prostate cancer. Thus, decreased risk observed in this study is biologically plausible.

Our sensitivity analysis showed that estimated SIRs of many major cancers were similar to those from the analysis, in which cancer cases identified in 1999 were excluded as well as cancer cases obtained from Registry for Catastrophic Illness database, except for stomach cancer. These consistent findings showed that the results of our study were robust. For several cancers with lower incidence rates, such as nasopharyngeal, small intestine, and brain cancers, SIR estimates based on Registry for Catastrophic Illness database are not consistent with those in the other two methods. The possible explanation for this inconsistency is that our sample size is not large enough for such low incidence rates that SIR estimates are not reliable enough. To be conservative, we only discussed cancer types with SIRs that are consistent with main and sensitivity analyses.

Our study showed men with a diagnosis of type $2 \mathrm{DM}$ were associated with increases in risks of liver, colorectal, oral, pancreatic, and kidney cancer incidences and women with a diagnosis of type 2 diabetes with increases in liver, colorectal, breast, pancreas, endometrium, bladder, and kidney cancers. These findings have important clinical implication: it is necessary to develop strategies of cancer-specific screening and prevention care in patients with type 2 diabetes for men and women. For future studies, what factors are associated with increased or decreased risks of site-specific cancer in patients with type 2 diabetes needs further investigation. In term of 
public health implication, we estimate that number of incident cases of liver, colorectal, pancreatic, and kidney cancers for men that can be attributable to type 2 diabetes by $272,50,194,28$, and 8 , respectively; number of incident cases of liver, colorectal, breast, pancreatic, bladder, and kidney cancers for women by 105, 21, 50, 11,4 , and 5, respectively, based on number of incident cases from Taiwan National Registry for Cancer in 2010 and SIRs and PAFs of type 2 diabetes indicated in our study. These findings provide information for health policy makers on evaluation of the cost-effectiveness of cancer screening and prevention program.

\section{Strengths and limitations}

This study has several merits. First, this study is considered a large study that involved estimation of SIRs for cancer patients with type 2 diabetes. Thus, this study has sufficient capability to detect the effect of type 2 diabetes and to adjust according to several risk factors, such as age, gender, insurance premium, and urbanization degree of area registered for $\mathrm{NIH}$ program through standardization. Although Asia Pacific Cohort Studies Collaboration (APCSC) has examined associations between diabetes and cancer mortality with a large sample size (Lam et al., [28]), our study has two advantages. One is that participants of APCSC are from thirty-six cohort Asian and Australasian studies with various ethnic origins, which may modify associations between diabetes and cancer incidences. The other is that APCSC has focused on cancer mortality, and cancer incidence has not been considered. Second, NHIRD included all diagnosed records. Thus, we can accurately determine cancer incidence and minimize the number of subjects in the cohort who were lost during follow-up period. Third, data with one-year left-censored for exploring the possibility of reverse causality had a negligible effect on original estimates. In addition, most of estimated SIRs are similar to those obtained from analysis, in which cancer incidences obtained from Registry for Catastrophic Illness database were used. The consistent findings from our sensitivity analysis indicated that our results are robust.

Several limitations of the study were also observed. First, we cannot obtain data of behavioral factors, such as smoking, alcohol consumption, obesity, body mass index, and physical activity. In addition, we cannot determine familial risks for diabetes to explain effects of genetic and environmental factors. Thus, independent effect of type 2 diabetes on cancer cannot be established. However, our study allows for rate comparison by adjusting for population structure of age, gender, insurance premium, and area registered for $\mathrm{NIH}$ program, which can be performed as the first step of this line of research. Second, diabetic patients may have taken medicine that affected cancer risks. Previous studies have also indicated that glucose-lowering medicines, such as metformin, may reduce risks of cancers in diabetic patients. On the contrary, sulfonylurea drugs or insulin are associated with increased cancer risks [46]. Thus the strength of association between type 2 diabetes and cancer estimated for different populations depend on prevalence of anti-diabetes medication in population with diabetes. Although we did not have information regarding glucose-lowering medications, it won't confound our estimation for association between type 2 diabetes and cancer in our population.

\section{Conclusion}

Our data suggested that unusual risks of cancer are associated with type 2 diabetes. Significant increased risks were observed in liver, colorectal, oral, pancreatic, and kidney cancers in men, and in liver, colorectal, breast, pancreatic, endometrium, bladder, and kidney cancers in women. Reduced risks were observed in prostate, esophageal, and laryngeal cancers in men. Reduced risks were also found in cervical and connective and other soft tissue cancers in women.

\section{Competing interests}

The authors declare that they have no competing interests.

\section{Authors' contributions}

$\mathrm{TCL}, J H C$ and $C C L$ contributed equally to the design of the study and the direction of its implementation, including supervision of the field activities, quality assurance and control. CIL, CSL, and WYL supervised the field activities. CSL, CCL, TFH and CIL helped conduct the literature review and prepare the Methods and the Discussion sections of the text. TCL and JHC designed the study's analytic strategy and conducted the data analysis. All authors read and approved the final manuscript.

\section{Acknowledgements}

This study was supported primarily by the Ministry of Science and Technology of Taiwan (National Science Council)(NSC 101-2314-B-039 -017MY3 \& NSC 102-2314-B-039-005-MY2), the China Medical University Hospital (DMR-103-103), Taiwan Ministry of Health and Welfare Clinical Trial and Research Center of Excellence (MOHW103-TDU-B-212-113002) and Health and welfare surcharge of tobacco products, China Medical University Hospital Cancer Research Center of Excellence (MOHW103-TD-B-111-03, Taiwan).

\section{Author details}

${ }^{1}$ Department of Family Medicine, China Medical University Hospital, Taichung, Taiwan. ${ }^{2}$ School of Medicine, College of Medicine, China Medical University, Taichung, Taiwan. ${ }^{3}$ Department of Medical Research, China Medical University Hospital, Taichung, Taiwan. ${ }^{4}$ Graduate Institute of Biostatistics, College of Management, China Medical University, 91 Hsueh-Shih Road, Taichung 40421, Taiwan. ${ }^{5}$ Health Promotion Administration, Ministry of Health and Welfare, Taipei, Taiwan. ${ }^{6}$ Division of Urology, Department of Surgery, Buddhist Tzu Chi General Hospital, Taichung Branch, Taichung, Taiwan. ${ }^{7}$ School of Medicine, Buddhist Tzu Chi University, Hualien, Taiwan. ${ }^{8}$ Graduate Institute of Clinical Medical Science, College of Medicine, China Medical University, Taichung, Taiwan.

${ }^{9}$ Department of Healthcare Administration, College of Health Science, Asia University, Taichung, Taiwan.

Received: 31 October 2013 Accepted: 20 May 2014

Published: 29 May 2014

\section{References}

1. World Health Organization (WHO): The World Health Report 2004: Changing History. 2004. Available: http://www.who.int/whr/2004/en/. 
2. Lin CC, Li Cl, Hsiao CY, Liu CS, Yang SY, Lee CC, Li TC: Time trend analysis of the prevalence and incidence of diagnosed type 2 diabetes among adults in Taiwan from 2000 to 2007: a population-based study. BMC Public Health 2013, 13:318.

3. Chang CH, Shau WY, Jiang YD, Li HY, Chang TJ, Sheu WH, Kwok CF, Ho LT, Chuang LM: T2DM prevalence and incidence among adults in Taiwan during 1999-2004: a national health insurance data set study. Diabet Med 2010, 27:636-643.

4. Health Promotion Administration, Ministry of Health and Welfare. Available: http://www.hpa.gov.tw/BHPNet/Web/HealthTopic/TopicArticle.aspx? id=201102140001\&parentid=200712250011.

5. Limburg PJ, Vierkant RA, Fredericksen ZS, Leibson CL, Rizza RA, Gupta AK, Ahlquist DA, Melton $\amalg$ 3rd, Sellers TA, Cerhan JR: Clinically confirmed T2DM mellitus and colorectal cancer risk: a population-based, retrospective cohort study. Am J Gastroenterol 2006, 101:1872-1879.

6. Hemminki K, Li X, Sundquist J, Sundquist K: Risk of cancer following hospitalization for T2DM. Oncologist 2010, 15:548-555.

7. El-Serag HB, Tran T, Everhart JE: Diabetes increases the risk of chronic liver disease and hepatocellular carcinoma. Gastroenterology 2004, 126:460-468.

8. Fujino Y, Mizoue T, Tokui N, Yoshimura T: Prospective study of diabetes mellitus and liver cancer in Japan. Diabetes Metab Res Rev 2001, 17:374-379.

9. Wang J, Webb G, Cao Y, Steiner DF: Contrasting patterns of expression of transcription factors in pancreatic alpha and beta cells. Proc Natl Acad Sci US A 2003, 100:12660-12665.

10. Gullo L, Pezzilli R, Morselli-Labate AM, Italian Pancreatic Cancer Study Group: Diabetes and the risk of pancreatic cancer. N Engl J Med 1994, 331:81-84.

11. Michels KB, Solomon CG, Hu FB, Rosner BA, Hankinson SE, Colditz GA, Manson JE: Nurses' health study. T2DM and subsequent incidence of breast cancer in the Nurses' health study. Diabetes Care 2003, 26:1752-1758

12. Waters KM, Henderson BE, Stram DO, Wan P, Kolonel LN, Haiman CA: Association of diabetes with prostate cancer risk in the multiethnic cohort. Am J Epidemiol 2009, 169:937-945

13. Li D, Yeung SC, Hassan MM, Konopleva M, Abbruzzese JL: Antidiabetic therapies affect risk of pancreatic cancer. Gastroenterology 2009, 137:482-488.

14. World Cancer Research Fund/American Institute for Cancer Research (WCRF/AICR): Food, Nutrition and the Prevention of Cancer: A Global Perspective. Washington DC: WCRF/AICR; 1997.

15. Schienkiewitz A, Schulze MB, Hoffmann K, Kroke A, Boeing H: Body mass index history and risk of T2DM : results from the European Prospective Investigation into Cancer and Nutrition (EPIC)-Potsdam Study. Am J Clin Nutr 2006, 84:427-433.

16. Considine RV, Premkumar A, Reynolds JC, Sebring NG, Ricks M, Sumner AE: Adiponectin and leptin in African Americans. Obesity (Silver Spring) 2008, 16:428-434

17. Giovannucci E, Harlan DM, Archer MC, Bergenstal RM, Gapstur SM, Habel LA, Pollak M, Regensteiner JG, Yee D: Diabetes and cancer: a consensus report. CA Cancer J Clin 2010, 60:207-221.

18. Ren X, Zhang X, Zhang X, Gu W, Chen K, Le Y, Lai M, Zhu Y: T2DM mellitus associated with increased risk for colorectal cancer: evidence from an international ecological study and population-based risk analysis in China. Public Health 2009, 123:540-544.

19. Wideroff L, Gridley G, Mellemkjaer L, Chow WH, Linet M, Keehn S, Borch-Johnsen $\mathrm{K}$, Olsen $\mathrm{JH}$ : Cancer incidence in a population-based cohort of patients hospitalized with diabetes mellitus in Denmark. J Nat/ Cancer Inst 1997, 89:1360-1365.

20. Tseng $\mathrm{CH}$ : Diabetes and risk of prostate cancer: a study using the National Health Insurance. Diabetes Care 2011, 34:616-621.

21. Huang YC, Lin JK, Chen WS, Lin TC, Yang SH, Jiang JK, Chang SC, Lan YT, Wang HS, Liu CY, Yang YW, Teng HW: Diabetes mellitus negatively impacts survival of patients with colon cancer, particularly in stage II disease. J Cancer Res Clin Oncol 2011, 137:211-220.

22. Chen HF, Chen P, Li CY: Risk of malignant neoplasms of liver and biliary tract in diabetic patients with different age and sex stratifications. Hepatology (Baltimore, Md) 2010, 52:155-163.

23. Tseng CH, Chong CK, Tai TY: Secular trend for mortality from breast cancer and the association between diabetes and breast cancer in Taiwan between 1995 and 2006. Diabetologia 2009, 52:240-246.

24. Lu JF, Hsiao WC: Does Universal health insurance make health care unaffordable? Lessons from Taiwan. Health Aff (Millwood) 2003, 22:77-88.

25. Liu CY, Hung YT, Chuang YL, Chen YJ, Weng WS, Liu JS, Liang KY: Incorporating development stratification of Taiwan townships into sampling design of large scale health interview survey. J Health Manag 2006, 4:1-22.

26. Rockhill B, Newman B, Weinberg C: Use and misuse of population attributable fractions. Am J Public Health 1998, 88(1):15-19.

27. Stephansson O, Granath F, Ekbom A, Michels KB: Risk of breast cancer among daughters of mothers with diabetes: a population-based cohort study. Breast Cancer Res 2010, 12:R14.

28. Lam EK, Batty GD, Huxley RR, Martiniuk AL, Barzi F, Lam TH, Lawes CM, Giles GG, Welborn T, Ueshima H, Tamakoshi A, Woo J, Kim HC, Fang X, Czernichow S, Woodward M, Asia Pacific Cohort Studies Collaboration: Associations of diabetes mellitus with site-specific cancer mortality in the Asia-Pacific region. Ann Oncol 2011, 22(3):730-738.

29. Balkau B, Kahn HS, Courbon D, Eschwège $E$, Ducimetière $P$, Paris Prospective Study: Hyperinsulinemia predicts fatal liver cancer but is inversely associated with fatal cancer at some other sites: the Paris Prospective Study. Diabetes Care 2001, 24:843-849.

30. Rousseau MC, Parent ME, Pollak MN, Siemiatycki J: Diabetes mellitus and cancer risk in a population-based case-control study among men from Montreal, Canada. Int J Cancer 2006, 118:2105-2109.

31. Coughlin SS, Calle EE, Teras LR, Petrelli J, Thun MJ: Diabetes mellitus as a predictor of cancer mortality in a large cohort of US adults. Am J Epidemiol 2004, 159:1160-1167.

32. Jee SH, Ohrr H, Sull JW, Yun JE, Ji M, Samet JM: Fasting serum glucose level and cancer risk in Korean men and women. JAMA 2005, 293:194-202.

33. Michaud DS, Liu S, Giovannucci E, Willett WC, Colditz GA, Fuchs CS: Dietary sugar, glycemic load, and pancreatic cancer risk in a prospective study. J Natl Cancer Inst 2002, 94:1293-1300.

34. Chari ST, Leibson CL, Rabe KG, Ransom J, de Andrade M, Petersen GM: Probability of pancreatic cancer following diabetes: a population-based study. Gastroenterology 2005, 129:504-511.

35. Rodriguez C, Patel AV, Mondul AM, Jacobs EJ, Thun MJ, Calle EE: Diabetes and risk of prostate cancer in a prospective cohort of US men. Am J Epidemiol 2005, 161:147-152.

36. Coker AL, Sanderson M, Zheng W, Fadden MK: Diabetes mellitus and prostate cancer risk among older men: population-based case-control study. Br J Cancer 2004, 90:2171-2175.

37. Bonovas S, Filioussi K, Tsantes A: Diabetes mellitus and risk of prostate cancer: a meta-analysis. Diabetologia 2004, 47:1071-1078.

38. Gonzalez-Perez A, Garcia Rodriguez LA: Prostate cancer risk among men with diabetes mellitus (Spain). Cancer Causes Control 2005, 16:1055-1058.

39. Tavani A, Gallus S, Bertuzzi M, Dal Maso L, Zucchetto A, Negri E, Francesch S, Ramazzotti V, Montella M, La Vecchia C: Diabetes mellitus and the risk of prostate cancer in Italy. Eur Urol 2005, 47:313-317.

40. Batty GD, Shipley MJ, Marmot M, Smith GD: Diabetes status and post-load plasma glucose concentration in relation to site-specific cancer mortality: findings from the original Whitehall study. Cancer Causes Control 2004, 15:873-881.

41. Weiderpass E, Ye W, Vainio H, Kaaks R, Adami HO: Diabetes mellitus and ovarian cancer (Sweden). Cancer Causes Control 2002, 13:759-764.

42. Park EJ, Lee JH, Yu GY, He G, Ali SR, Holzer RG, Osterreicher CH, Takahashi H, Karin M: Dietary and genetic obesity promote liver inflammation and tumorigenesis by enhancing IL-6 and TNF expression. Cell 2010, 140:197-208.

43. Coffey DS: Physiological control of prostatic growth: an overview. In: Prostate Cancer. Geneva Switzerland: Int Union Against Cancer 1979, 48:4-23.

44. Gann PH, Hennekens CH, Ma J, Longcope C, Stampfer MJ: Prospective study of sex hormone levels and risk of prostate cancer. J Natl Cancer Inst 1996, 88:1118-1126.

45. Haffner SM, Shaten J, Stern MP, Smith GD, Kuller L: Low levels of sex hormone-binding globulin and testosterone predict the development of non-insulin-dependent diabetes mellitus in men: Multiple Risk Factor Intervention Trial. Am J Epidemiol 1996, 143:889-897.

46. Donadon V, Balbi M, Ghersetti M, Grazioli S, Perciaccante A, Della Valentina G, Gardenal R, Dal Mas M, Casarin P, Zanette G, Miranda C: Antidiabetic therapy and increased risk of hepatocellular carcinoma in chronic liver disease. World J Gastroenterol 2009, 15:2506-2511.

doi:10.1186/1471-2407-14-381

Cite this article as: Lin et al:: Cancer risks among patients with type 2 diabetes: a 10-year follow-up study of a nationwide population-based cohort in Taiwan. BMC Cancer 2014 14:381. 